\title{
New Approaches to Dermatological Conditions Employing Mesenchymal Stem Cell Therapies
}

\author{
Nunez Naveira L, Rodriguez Garcia MI, Hermida Prieto $\mathbf{M}^{*}$ and \\ Marinas Pardo L \\ Centauri Biotech, Spain
}

*Corresponding author: Manuel Hermida-Prieto, Centauri Biotech, S.L., C/ Asunción s/n, 1ํ Izq, 15142, Meicende Arteixo, A Coruña, Spain, Tel: +34 881993 722;

Email: manuel.hermida@centauribiotech.com

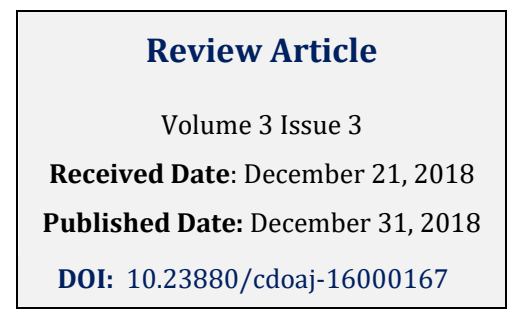

\section{Abstract}

Mesenchymal stem cells (MSCs) are multipotent stem cells with the capacity to differentiate in vitro into diverse cell lineages and secrete different bioactive molecules with trophic, paracrine and immunomodulatory functions. On the other hand, skin inflammation may be a sign of allergic, autoimmune, or infectious conditions and it is observed in several diseases such as atopic dermatitis, cutaneous graft versus host disease, cutaneous lupus erythematosus, psoriasis and systemic sclerosis.

Traditional therapies for these skin diseases are not completely effective and have potential systemic adverse events. Consequently, new safer therapies need to be developed, being MSCs a value alternative. Due to the lack of knowledge on MSCs mode of action, animal models of disease help to discern their mechanism of immunoregulation and improve their safety after their application.

The literature supports that MSCs act by a paracrine via by using anti-inflammatory cytokines targeting specifically those cells involved in the inflammation of immune-regulated diseases. Consequently, MSCs reduce the excessive immune responses and protect the adjacent tissues.

Keywords: Atopic dermatitis; Cutaneous graft versus host disease; Cutaneous lupus erythematosus; Mesenchymal stem cell; Psoriasis; Systemic sclerosis

\section{Introduction}

Skin inflammation may be a sign of allergic, autoimmune, or infectious conditions. Atopic dermatitis (AD), contact dermatitis, and urticaria (hives) are examples of allergic skin conditions whilst psoriasis and acne are considered primarily inflammatory in nature [1]. $\mathrm{AD}$ and psoriasis have increased their prevalence in industrialized countries due to the higher level of contamination [2], which resulted in a considerable psychosocial and economic burden for patients and their families [3-5].

$\mathrm{AD}$ is a common, clinically defined skin disease frequently associated with allergic rhinitis, asthma, and immunoglobulin E (IgE)-mediated food reactions [6]. The 
traditional treatment for $\mathrm{AD}$ is based in topical antiinflammatory agents (corticosteroids), that provide a short-term benefit but long-term remission is difficult to achieve [7].

Psoriasis is a lifelong, chronic, and immune-mediated systemic disease with preferential skin involvement. It is characterized by excessive growth and aberrant differentiation of keratinocytes through the activation of the cellular immune system, with $\mathrm{T}$ cells, dendritic cells and various immune-related cytokines and chemokines implicated in pathogenesis. Topical corticosteroids is the mainstay of treatment for psoriasis due to their immunosuppressive, anti-inflammatory and antiproliferative properties [8].

Although corticosteroids are the traditional therapy for these skin diseases, they have cutaneous adverse effects such as atrophy, striae and/or telangiectases, and also potential systemic adverse events. Consequently, long-term utilization is not recommended [9] and alternative and safer therapies are being applied.

Mesenchymal stem cells (MSC) have been exploited for their immunomodulatory properties in the treatment of a number of immune-based disorders [10], and different works in recent years have shown their possible use in dermatological diseases. That is why we will focus this review on the main characteristics of these cells and their possible mechanism of action in specific dermatological pathologies.

\section{Mesenchymal Stem Cells}

\section{Sources of MSCs}

MSCs were originally isolated from the bone marrow [11], but later they have been obtained from nearly all tissues of the body, including adipose tissue [12,13], umbilical cord blood [14], umbilical cord Wharton's jelly [15,16], allanto-amniotic membranes [17], synovia [18], periost [13], skeletal muscle [13], teeth [19], placenta [20] or endometrium [21]. All of them were sources of MSCs, as determined by morphology, adherence to plastic, trilineage differentiation, and detection of stem cell surface markers with immunofluorescent and flow cytometric analyses.

The two more abundant sources for MSCs are foetal umbilical cord matrix (Wharton's jelly) and adult adipose tissue [15]. Although both sources show potential for their application in biomedicine, the number of scientific publications based on the use of adipose-tissue derived MSCs (5469 publications in PubMed, accessed December 2018 the $\left.26^{\text {th }}\right)$ overpass those using Wharton's jelly MSCs (712 publications in PubMed, accessed December 2018 the $26^{\text {th }}$ ). Consequently, and because they are the main objective of the authors research, this review is mainly focussed on adipose tissue derived MSCs. The stem cells derived from adipose tissue are similar to bone marrowderived MSCs in morphology and phenotype, but show some differences [22]. Adipose tissue collection is less traumatic and the presence of MSCs in this tissue is higher than bone marrow. Consequently, adipose tissue MSCs are a promising source for regenerative medicine (Figure 1).

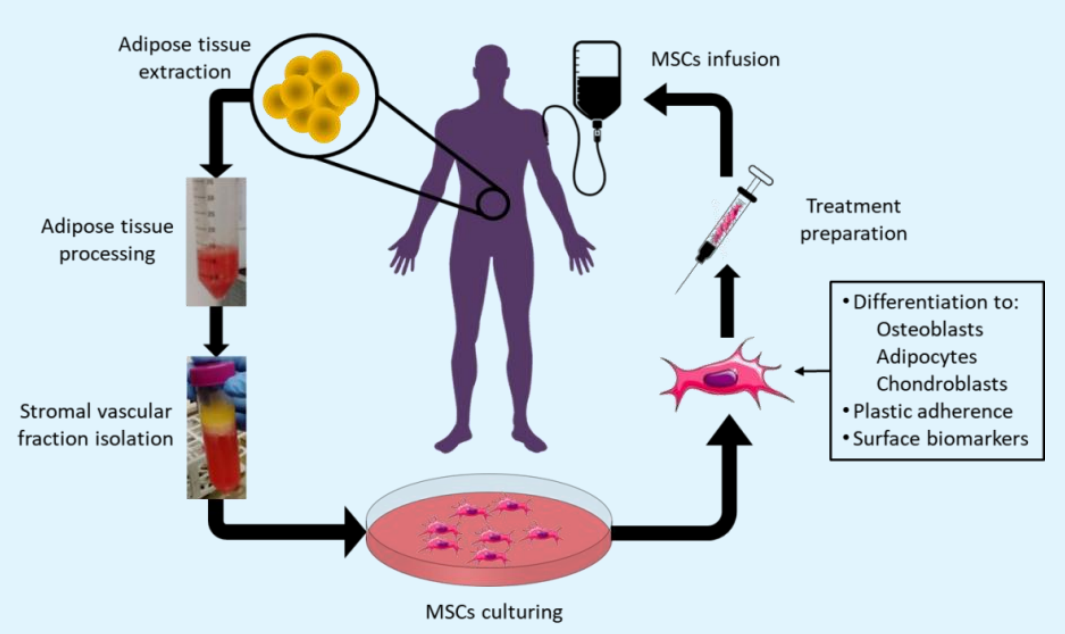

Figure 1: Schematic representation of the procedure for MSCs treatment from adipose tissue extraction to cells infusion. 


\section{Characterization of MSCs}

The International Society for Cellular Therapy (ISCT) established the minimal criteria to define human mesenchymal stem cells (MSCs) in order to allow the comparison of results among different studies: (i) MSCs must be plastic-adherent when maintained in standard culture conditions; (ii) MSCs must express CD105, CD73 and CD90, and lack expression of CD45, CD34, CD14 or CD11b, CD79a or CD19 and HLA-DR surface molecules; (iii) MSCs must differentiate into osteoblasts, adipocytes and chondroblasts in vitro $[23,24]$.

\section{General Mode of Action}

Despite the capacity of MSCs to differentiate, growing evidence suggests that disease-modifying activity of MSCs is due to different products secreted by the cells in response to environmental niche stimuli $[25,26]$ (Figure 2). This paracrine signalling mechanism by MSCs might be more important than differentiation in stimulating repair responses [27] and makes allogeneic MSCs a suitable therapy for many diseases, due to the possibility of infusion without a substantial risk of immune rejection. Differentiation to specialized cell types, would change MSCs phenotype making them prone be detected and deleted by the host immune system. Since paracrine mechanism is active in a stemness state, it is not affected by the host immune system.

MSCs exhibit immunosuppressive effects on MHCmismatched lymphocytes proliferation and these cells can also inhibit naive, memory and activated $\mathrm{T}$ cells, B cells, natural killer cells and dendritic cells $[28,29]$.

MSCs have a trophic, anti-inflammatory and immunosuppressive action, by modulating $\mathrm{T}$ and $\mathrm{B}$ cells and inducing the expression of anti-inflammatory factors, and among them transforming growth factor (TGF)- $\beta 1$ [30].

TGF- $\beta$ is widely expressed in a variety of tissues and local production of TGF- $\beta$ is a potent mechanism of immune suppression in a variety of contexts. MSC production of TGF- $\beta$ has been demonstrated in MSCs derived from numerous tissues including adipose [31], being the essential contribution of TGF- $\beta$ the suppression of T cell proliferation [32].

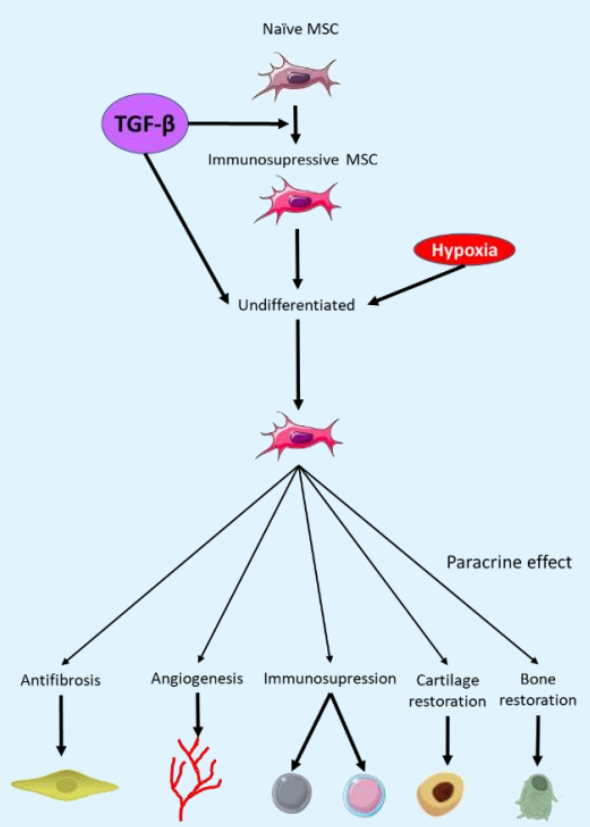

Figure 2: Mode of action for MSCs highlighting their paracrine effect.

\section{Allogeneic vs Autologous MSCs Use}

MSCs express low levels of major histocompatibility complex class I (MHC-I) but lack expression of MHC-II surface molecules. Their low immunogenicity and their immunomodulatory potential allow their allogeneic use, which makes them a promising new treatment for severe refractory autoimmune diseases [28,33-37].

Although the majority of clinical trials listed on www.clinicaltrials.gov test the efficacy in humans of autologous MSCs (more than 300), the number of clinical trials testing allogeneic MSCs efficacy has increased reaching more than 200 studies.

\section{Therapeutic Use of MSCs in Skin Diseases}

There are currently many registered clinical trials (https://clinicaltrials.gov/) about the therapeutic use of the MSCs in different skin diseases (Table 1). This is a proof of their potential as cell therapy in dermatologic conditions. 


\section{Clinical Dermatology Open Access Journal}

\begin{tabular}{|c|c|c|c|}
\hline $\begin{array}{c}\text { ClinicalTrials.gov } \\
\text { Identifier }\end{array}$ & Intervention & Phase & Condition \\
\hline NCT02888704 & BM-derived adult human MSC & Phase 1 & Atopic Dermatitis \\
\hline NCT03252340 & BM-derived adult human MSCs & Not Applicable & Atopic Dermatitis \\
\hline NCT03765957 & Umbilical cord blood-derived MSCs & Early phase 1 & Psoriasis \\
\hline NCT03745417 & Umbilical cord-derived MSCs & Phase 1/Phase 2 & Psoriasis \\
\hline NCT02491658 & Umbilical cord-derived MSCs & Phase 1/Phase 2 & Psoriasis Vulgaris \\
\hline NCT03265613 & Adipose-derived multipotent MSCs & Phase 1/Phase 2 & Psoriasis \\
\hline NCT03392311 & Adipose-derived multipotent MSCs & Phase $1 /$ Phase 2 & Psoriasis \\
\hline \multirow{2}{*}{ NCT03424629 } & Low-dose umbilical cord-derived MSCs & \multirow{2}{*}{ Phase 1} & \multirow{2}{*}{$\begin{array}{l}\text { Moderate and Severe Plaque } \\
\text { Psoriasis }\end{array}$} \\
\hline & High-dose umbilical cord derived MSCs & & \\
\hline NCT02918123 & $\begin{array}{l}\text { Allogeneic human umbilical cord blood- } \\
\text { derived MSCs }\end{array}$ & Phase 1 & Psoriasis \\
\hline NCT01765634 & BM-derived MSCs & Phase 2 & Acute GvHD \\
\hline NCT01765660 & BM-derived MSCs & Phase 2 & Chronic GvHD \\
\hline NCT01956903 & BM-derived allogenic MSCs & Phase $1 /$ Phase 2 & Chronic GvHD \\
\hline NCT00972660 & BM-derived MSCs & Phase 2 & GvHD \\
\hline NCT01526850 & BM-derived MSCs & Phase 2/Phase 3 & Chronic GvHD \\
\hline NCT01222039 & Adipose-derived allogenic MSCs & Phase $1 /$ Phase 2 & GvHD \\
\hline NCT00366145 & BM-derived MSCs & Phase 3 & GvHD \\
\hline NCT00314483 & MSCs infusion (MSCs origin not specified) & Phase 1/Phase 2 & GvHD \\
\hline NCT01941394 & BM-derived MSCs & Phase 2 & GvHD \\
\hline NCT00447460 & BM-derived MSCs & Phase 1/Phase 2 & GvHD \\
\hline NCT03219801 & Umbilical cord-derived MSCs & Early phase 1 & SLE \\
\hline NCT03171194 & Low-dose umbilical cord-derived MSCs & Phase 1 & SLE \\
\hline NCT03562065 & Umbilical cord-derived MSCs & Phase 1/Phase 2 & Lupus Erythematosus \\
\hline \multirow{2}{*}{ NCT02633163 } & Low-dose umbilical cord-derived MSCs & \multirow{2}{*}{ Phase 2} & \multirow{2}{*}{ SLE } \\
\hline & High-dose umbilical cord-derived MSCs & & \\
\hline NCT00698191 & BM-derived allogeneic MSCs & Phase 1/Phase 2 & Refractory SLE \\
\hline NCT01741857 & Human umbilical cord-derived MSCs & Phase $1 /$ Phase 2 & SLE \\
\hline NCT03673748 & BM-derived MSCs & Phase 2 & Lupus Erythematosus \\
\hline NCT02213705 & Allogeneic MSCs (MSCs origin not specified) & Phase $1 /$ Phase 2 & Systemic Scleroderma \\
\hline NCT00962923 & Umbilical cord-derived allogeneic MSCs & Phase $1 /$ Phase 2 & Systemic Sclerosis \\
\hline NCT02975960 & $\begin{array}{l}\text { Autologous stromal vascular fraction } \\
\text { (adipose tissue) }\end{array}$ & Not Applicable & Systemic Sclerosis \\
\hline NCT03211793 & BM-derived MSCs & Phase 1/Phase 2 & Systemic Sclerosis \\
\hline
\end{tabular}

Table 1: Registered clinical trials testing MSCs on dermatological conditions.

BM: Bone marrow; GvHD: Graft-versus-host disease: SLE: Systemic lupus erythematosus; MSCs: Mesenchymal stem (or stromal) cells.

\section{Atopic Dermatitis}

MSCs have been extensively studied as a cellular therapy for different pathological conditions using the dog as an animal model [34,37-41]. There are currently many studies in both, animals and human beings, which demonstrate the efficacy of MSCs in atopic dermatitis $[42,43]$. Our research group showed that systemic administration of allogeneic MSCs appeared to be a simple therapy with positive outcome in the remission of clinical signs for canine AD refractory to conventional medications, for at least six months and with no adverse events [44].

Allogeneic use of MSCs is an alternative to autologous when limiting factors such as age, medications and 
concomitant diseases, may have an impact on the quality and immunomodulatory capacity of autologous therapy [45].

Recently, human MSCs derived from different tissues affected by $\mathrm{AD}$ showed immunomodulatory profile differences compared with healthy subjects, evidencing that MSCs could be involved in the AD pathogenesis [46] as it has been described in other immune-mediated diseases [47-49]. This would support the idea of an allogeneic MSCs therapy in AD [42].

Considering that the dog develops AD naturally with cutaneous clinical characteristics similar to the human beings, despite some differences, [50-53] dogs might serve as a partial model for human AD therapy with cellbased regenerative strategies.
Different in vivo studies evidenced that systemically infused MSCs homing to injured and inflamed tissues resulted in a positive therapeutic effect [43,54-56]. In AD, MSCs migrate to skin lesions through draining lymph nodes [43] and decrease physiological migration of interstitial dendritic cells from skin to lymph nodes. At the same time, MSCs decrease cell infiltration in the skin lesion reducing generation of effector $\mathrm{T}$ cells [43]. Dendritic cells are the most potent type of antigenpresenting cells and play crucial roles in the initiation and control of the adaptive immune responses [57]. In addition, some MSCs may remain in secondary lymphoid organs to block the migration of effector $\mathrm{T}$ cells to the inflamed region $[43,57]$ (Figure 3).

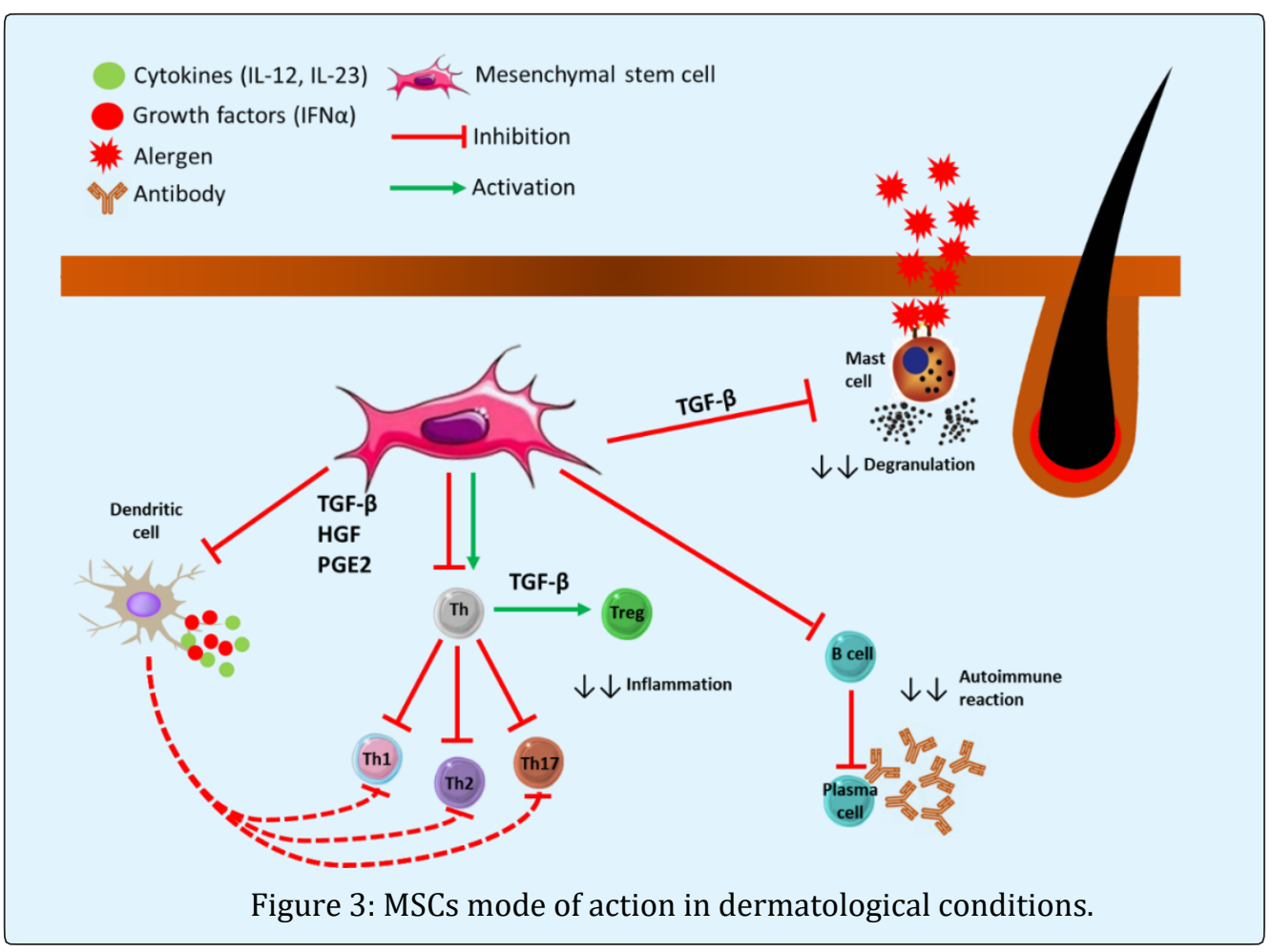

\section{Psoriasis}

Human psoriasis, in contrast to $\mathrm{AD}$, is characterized by the lack of a naturally occurring disorder in animals [58], making difficult to test new biological therapies effect on the disease. Nevertheless, animal models of psoriasis have helped to find out the biological functions of inflammatory mediators, adaptive immune mechanisms, keratinocytes, and endothelial cells.
Dendritic cells (DCs) and T cell-mediated immune responses are key actors in the psoriasis development being Th1 and Th17 subsets the primary effector cells [59]. DCs produce interferon $\alpha$ (IFN- $\alpha$ ) and interleukins (IL-12, IL-23) that drive the differentiation of Th1 and Th17 cells, leading to the onset of psoriasis.

MSCs from patients with psoriasis showed impaired anti-inflammatory function against Th cell subsets [60], 


\section{Clinical Dermatology Open Access Journal}

suggesting that allogeneic MSC therapy could be beneficial in treating psoriasis. Previous preclinical studies demonstrated that MSCs efficiently attenuates skin inflammation in mice via suppression of Th1, Th2 and Th17 differentiation and up-regulating Treg population [61] (Figure 3).

\section{Cutaneous Graft Versus Host Disease (GvHD)}

Chronic graft-versus-host disease (GvHD) is the major cause of morbidity and mortality in those patients that received allogeneic hematopoietic cell transplantation. In this disease, $\mathrm{T}$ cells transferred from donor recognize host HLA molecules as non-self and generate an immune response [62]. Current immunosuppressive drugs are not effective to treat chronic GvHD and there is a significant impediment to progress in treating chronic GvHD due to the lack of existing animal models.

T cells can differentiate into Th1, Th2 and Th17 subsets in response to the environment cytokines. The different T cells subsets play a role in GvHD development and recent animal models research have explained how Th1 cells are major effector cells in acute GvHD, although Th2 cells and IL-22-producing CD4+ T cells are also actors in this condition. Th17 and Treg cells and also B cells might contribute to the development of the disease [63]. MSCs can inhibit the proliferation and differentiation of $\mathrm{T}$ lymphocytes through various mechanisms, including secretion of soluble mediators such as hepatocyte growth factor (HGF), transforming growth factor $\beta 1$ (TGF- $\beta 1$ ) and prostaglandin E2 (PGE2) [64,65] (Figure 3).

Prochymal@ (remestemcel-L) is the first stem cell therapy approved by Canada for GvHD. It is an allogenic stem therapy based on bone marrow derived MSCs that demonstrated a statistically important improvement in survival, with the largest benefit of survival being noted in those with the most severe forms of GvHD [66].

\section{Cutaneous Lupus Erythematosus}

Lupus erythematosus is an autoimmune chronic inflammatory disease that can affect every organ. It triggers among others the cutaneous lupus erythematosus when the skin is predominantly affected. In this skin condition, specific antibodies are produced and cause damage to the skin resulting in the appearance of a rash. Complex cascades of native skin cells, such as endothelial cells, keratinocytes, and immune cells, especially Th1 cells, neutrophils and polyclonal B cells, are known to be implicated in cutaneous inflammation [67].
Mutated mice have been widely used as experimental animal models of lupus erythematosus to explore the therapeutic potential of MSCs, showing a down-regulated $B$ cell activation and maturation through soluble mediators [68] (Figure 3).

In humans, MSC-based therapies have shown to trigger remission in patients with refractory systemic lupus erythematosus including skin manifestations [69].

\section{Systemic Sclerosis}

Systemic sclerosis is an autoimmune disorder where healthy tissue is destroyed by the own immune system. Systemic sclerosis is characterized by changes in the texture and appearance of the skin due to increased collagen production [70]. The immunological responses in patients with systemic sclerosis are predominated by Th2 cells and relevant cytokines like IL-4 and IL-13, which contributes to the formation of pro-fibrotic microenvironment [71]. Due to the different features and complexity of pathogenesis, currently there are no satisfactory therapeutic approaches for systemic sclerosis that keeps higher rates of morbidity and mortality [72].

MSCs show anti-fibrotic, anti-oxidant and immunomodulatory capabilities for skin lesions as well as lung injuries in murine models of disease [73]. MSCs were able to mediate T-cell apoptosis, trigger macrophages to produce TGF- $\beta 1$ and finally up-regulate Treg cells population [74] (Figure 3).

Despite that the animal models did not reproduce perfectly the human disease condition, the results are enough to expect clinical benefit of MSC transplantation in patients with systemic sclerosis. In fact, transplantation of MSCs triggered a significant improvement in tightening of the skin without complications, thus suggesting they are a potentially valuable skin therapy in systemic sclerosis [75].

\section{Conclusion}

Research in stem cell-based therapies is increasing thus promising a great impact of this cell-based treatment on the medicine of the $21^{\text {st }}$ century. Current studies on the use of MSCs are not only exponentially increasing but also broadening their target conditions, so they can be applied to various skin diseases. Anyhow, most of the works are focused on the potential of MSCs to treat immunomodulated skin diseases through their paracrine effect. 
MSCs can be obtained from different tissue sources, but adipose tissue-derived MSCs have some advantages such as: (1) their abundance in donors and (2) their convenient isolation by less invasive and traumatic methods.

Normally, in research for drugs and other cell therapies there is a comprehensive understanding of the therapeutic mechanism before their clinical application. Nevertheless, MSCs have been successfully applied despite a limited understanding of their in vivo function under normal physiological conditions. Given that the current understanding of MSCs mode of action is still limited, the use of animal models of disease will help to discern not only their mechanism of immunoregulation but also improve their safety and reduce the adverse events after their application.

MSCs act by a paracrine via by using antiinflammatory cytokines targeting specifically those cells involved in the inflammation of immune-regulated diseases. Consequently, MSCs reduce the excessive immune responses and protect the adjacent tissues.

\section{References}

1. Wollenberg A, Feichtner K (2013) Atopic dermatitis and skin allergies - update and outlook. Allergy 68(12): 1509-1519.

2. Silverberg JI, Hanifin JM (2013) Adult eczema prevalence and associations with asthma and other health and demographic factors: A US populationbased study. J Allergy Clin Immunol 132(5): 11321138.

3. Filanovsky MG, Pootongkam S, Tamburro JE, Smith MC, Ganocy SJ, et al. (2016) The Financial and Emotional Impact of Atopic Dermatitis on Children and Their Families. J Pediatr 169: 284290.e5.

4. Blome C, Radtke MA, Eissing L, Augustin M (2016) Quality of Life in Patients with Atopic Dermatitis: Disease Burden, Measurement, and Treatment Benefit. Am J Clin Dermatol 17(2): 163-169.

5. Sicras-Mainar A, Navarro-Artieda R, Carrascosa Carrillo JM (2018) Economic Impact of Atopic Dermatitis in Adults: A Population-Based Study (IDEA Study). Actas Dermo-Sifiliográficas 109(1): 35-46.
6. Bieber $\mathrm{T}$ (2010) Atopic Dermatitis. Ann Dermatol 22(2): 125-137.

7. Darsow U, Wollenberg A, Simon D, Taïeb A, Werfel T, et al. (2010) ETFAD/EADV eczema task force 2009 position paper on diagnosis and treatment of atopic dermatitis. J Eur Acad Dermatology Venereol 24(3): 317-328.

8. Lowes MA, Bowcock AM, Krueger JG (2007) Pathogenesis and therapy of psoriasis. Nature 445(7130): 866-873.

9. Schoepe S, Schacke H, May E, Asadullah K (2006) Glucocorticoid therapy-induced skin atrophy. Exp Dermatol 15(6): 406-420.

10. Lalu MM, McIntyre L, Pugliese C, Fergusson D, Winston BW, Marshall JC, et al. (2012) Safety of Cell Therapy with Mesenchymal Stromal Cells (SafeCell): A Systematic Review and Meta-Analysis of Clinical Trials. PLoS One 7(10): e47559.

11. Pittenger MF, Mackay AM, Beck SC, Jaiswal RK, Douglas R, et al. (1999) Multilineage potential of adult human mesenchymal stem cells. Science 284(5411): 143-147.

12. González-Fernández ML, Pérez-Castrillo $S$, SánchezLázaro JA, Prieto-Fernández JG, López-González ME, et al. (2015) Assessment of regeneration in meniscal lesions by use of mesenchymal stem cells derived from equine bone marrow and adipose tissue. Am J Vet Res 77(7): 779-788.

13. Radtke CL, Nino-Fong R, Esparza Gonzalez BP, Stryhn $\mathrm{H}$, McDuffee LA (2013) Characterization and osteogenic potential of equine muscle tissue- and periosteal tissue-derived mesenchymal stem cells in comparison with bone marrow- and adipose tissuederived mesenchymal stem cells. Am J Vet Res 74(5): 790-800.

14. Koch TG, Heerkens T, Thomsen PD, Betts DH (2007) Isolation of mesenchymal stem cells from equine umbilical cord blood. BMC Biotechnol 7: 26 .

15. Christodoulou I, Kolisis FN, Papaevangeliou D, Zoumpourlis V (2013) Comparative Evaluation of Human Mesenchymal Stem Cells of Fetal (Wharton's Jelly) and Adult (Adipose Tissue) Origin during Prolonged In Vitro Expansion: Considerations for Cytotherapy. Stem Cells Int 2013: 246134. 
16. Christodoulou I, Goulielmaki M, Devetzi M, Panagiotidis M, Koliakos G, et al. (2018) Mesenchymal stem cells in preclinical cancer cytotherapy: a systematic review. Stem Cell Res Ther 9(1): 336.

17. Lange-Consiglio A, Corradetti B, Bizzaro D, Magatti M, Ressel L, et al. (2011) Characterization and potential applications of progenitor-like cells isolated from horse amniotic membrane. J Tissue Eng Regen Med 6: 622-635.

18. Prado AAF, Favaron PO, da Silva LCLC, Baccarin RYA, Miglino MA, et al. (2015) Characterization of mesenchymal stem cells derived from the equine synovial fluid and membrane. BMC Vet Res 11: 281.

19. Miura M, Gronthos S, Zhao M, Lu B, Fisher LW, et al. (2003) SHED: Stem cells from human exfoliated deciduous teeth. Proc Natl Acad Sci 100(10): 58075812 .

20. Abumaree MH, Abomaray FM, Alshabibi MA, AlAskar AS, Kalionis B (2017) Immunomodulatory properties of human placental mesenchymal stem/stromal cells. Placenta 59: 87-95.

21. Rink BE, Amilon KR, Esteves CL, French HM, Watson $E$, et al. (2017) Isolation and characterization of equine endometrial mesenchymal stromal cells. Stem Cell Res Ther 8: 166.

22. Markarian CF, Frey GZ, Silveira MD, Chem EM, Milani $\mathrm{AR}$, et al. (2014) Isolation of adipose-derived stem cells: a comparison among different methods. Biotechnol Lett 36(4): 693-702

23. Dominici M, Le Blanc K, Mueller I, Slaper-Cortenbach I, Marini F, et al. (2006) Minimal criteria for defining multipotent mesenchymal stromal cells. The International Society for Cellular Therapy position statement. Cytotherapy 8(4): 315-317.

24. De Schauwer C, Meyer E, Van de Walle GR, Van Soom A (2011) Markers of stemness in equine mesenchymal stem cells: a plea for uniformity. Theriogenology 75: 1431-1443.

25. Lange Consiglio A, Rossi D, Tassan S, Perego R, Cremonesi F, et al. (2013) Conditioned medium from horse amniotic membrane-derived multipotent progenitor cells: immunomodulatory activity in vitro and first clinical application in tendon and ligament injuries in vivo. Stem Cells Dev 22(22): 3015-3024.
26. Zhang H, Qiu X, Shindel AW, Ning H, Ferretti L, et al. (2012) Adipose Tissue-Derived Stem Cells Ameliorate Diabetic Bladder Dysfunction in a Type II Diabetic Rat Model. Stem Cells Dev 21(9): 1391-1400.

27. Barry F, Murphy M (2013) Mesenchymal stem cells in joint disease and repair. Nat Rev Rheumatol 9(10): 584-594.

28. Klinker MW, Wei CH (2015) Mesenchymal stem cells in the treatment of inflammatory and autoimmune diseases in experimental animal models. World J Stem Cells 7: 556-567.

29. Carrade DD, Borjesson DL (2013) Immunomodulation by mesenchymal stem cells in veterinary species. Comp Med 63(3): 207-217.

30. Puissant B, Barreau C, Bourin P, Clavel C, Corre J, Bousquet $C$, et al. (2005) Immunomodulatory effect of human adipose tissue-derived adult stem cells: comparison with bone marrow mesenchymal stem cells. Br J Haematol 129: 118-129.

31. Melief SM, Zwaginga JJ, Fibbe WE, Roelofs H (2013) Adipose tissue-derived multipotent stromal cells have a higher immunomodulatory capacity than their bone marrow-derived counterparts. Stem Cells Transl Med 2(6): 455-463.

32. Zhao ZG, Li WM, Chen ZC, You Y, Zou P (2008) Immunosuppressive Properties of Mesenchymal Stem Cells Derived from Bone Marrow of Patients with Chronic Myeloid Leukemia. Immunol Invest Taylor \& Francis 37(7): 726-739.

33. Gazdic M, Volarevic V, Arsenijevic N, Stojkovic M (2015) Mesenchymal Stem Cells: A Friend or Foe in Immune-Mediated Diseases. Stem Cell Rev Reports 11(2): 280-287.

34. Pérez-Merino EM, Usón-Casaús JM, Zaragoza-Bayle C, Duque-Carrasco J, Mariñas-Pardo L, et al. (2015) Safety and efficacy of allogeneic adipose tissuederived mesenchymal stem cells for treatment of dogs with inflammatory bowel disease: Clinical and laboratory outcomes. Vet J 206: 385-390.

35. Shin TH, Kim HS, Choi SW, Kang K-S, Shin TH, et al. (2017) Mesenchymal Stem Cell Therapy for Inflammatory Skin Diseases: Clinical Potential and Mode of Action. Int J Mol Sci 18(2): 244. 
36. Villatoro AJ, Fernández V, Claros S, Alcoholado C, Cifuentes M, et al. (2017) Regenerative Therapies in Dry Eye Disease: From Growth Factors to Cell Therapy. Int J Mol Sci 18: 2264.

37. Villatoro AJ, Fernández V, Claros S, Rico-Llanos GA, Becerra J, et al. (2015) Use of Adipose-Derived Mesenchymal Stem Cells in Keratoconjunctivitis Sicca in a Canine Model. Biomed Res Int 527926: 1-10.

38. Harman R, Carlson K, Gaynor J, Gustafson S, Dhupa S, et al. (2016) A Prospective, Randomized, Masked, and Placebo-Controlled Efficacy Study of Intraarticular Allogeneic Adipose Stem Cells for the Treatment of Osteoarthritis in Dogs. Front Vet Sci 3: 81.

39. Kim JW, Lee JH, Lyoo YS, Jung DI, Park HM (2013) The effects of topical mesenchymal stem cell transplantation in canine experimental cutaneous wounds. Vet Dermatol 24(2): 242-e53.

40. Hiyama A, Mochida J, Iwashina T, Omi H, Watanabe T, et al. (2008) Transplantation of mesenchymal stem cells in a canine disc degeneration model. J Orthop Res 26(5): 589-600.

41. Park SS, Lee YJ, Lee SH, Lee D, Choi K, et al. (2012) Functional recovery after spinal cord injury in dogs treated with a combination of Matrigel and neuralinduced adipose-derived mesenchymal Stem cells. Cytotherapy 14(4): 584-597.

42. Kim HS, Lee JH, Roh KH, Jun HJ, Kang KS, et al. (2017) Clinical Trial of Human Umbilical Cord Blood-Derived Stem Cells for the Treatment of Moderate-to-Severe Atopic Dermatitis: Phase I/IIa Studies. Stem Cells 35(1): 248-255.

43. Na K, Yoo HS, Zhang YX, Choi MS, Lee K, et al. (2014) Bone marrow-derived clonal mesenchymal stem cells inhibit ovalbumin-induced atopic dermatitis. Cell Death Dis 5: e1345-e1345.

44. Villatoro AJ, Hermida-Prieto M, Fernández V, Fariñas F, Alcoholado C, et al. (2018) Allogeneic adiposederived mesenchymal stem cell therapy in dogs with refractory atopic dermatitis: clinical efficacy and safety. Vet Rec 183(21): 654.

45. Kizilay Mancini O, Shum-Tim D, Stochaj U, Correa JA, Colmegna I (2015) Age, atherosclerosis and type 2 diabetes reduce human mesenchymal stromal cellmediated T-cell suppression. Stem Cell Res Ther 6: 140.
46. Orciani M, Campanati A, Caffarini M, Ganzetti G, Consales V, et al. (2017) T helper (Th)1, Th17 and Th2 imbalance in mesenchymal stem cells of adult patients with atopic dermatitis: at the origin of the problem. Br J Dermatol 176(6): 1569-1576.

47. Orciani M, Campanati A, Salvolini E, Lucarini G, Di Benedetto G, et al. (2011) The mesenchymal stem cell profile in psoriasis. Br J Dermatol 165(3): 585-592.

48. de Lima KA, de Oliveira GL V, Yaochite JNU, Pinheiro DG, de Azevedo JTC, et al. (2016) Transcriptional profiling reveals intrinsic mRNA alterations in multipotent mesenchymal stromal cells isolated from bone marrow of newly-diagnosed type 1 diabetes patients. Stem Cell Res Ther 7: 92.

49. De Oliveira GL V, De Lima KWA, Colombini AM, Pinheiro DG, Panepucci RA, et al. (2015) Bone Marrow Mesenchymal Stromal Cells Isolated from Multiple Sclerosis Patients have Distinct Gene Expression Profile and Decreased Suppressive Function Compared with Healthy Counterparts. Cell Transplant 24(2): 151-165.

50. Hauck V, Hügli $P$, Meli ML, Rostaher A, Fischer N, et al. (2016) Increased numbers of FoxP3-expressing CD4+ CD25+ regulatory $\mathrm{T}$ cells in peripheral blood from dogs with atopic dermatitis and its correlation with disease severity. Vet Dermatol 27(1): 26-e9.

51. Majewska A, Gajewska M, Dembele K, Maciejewski $H$, Prostek A, et al. (2016) Lymphocytic, cytokine and transcriptomic profiles in peripheral blood of dogs with atopic dermatitis. BMC Vet Res 12(1): 174.

52. Olivry T, Mayhew D, Paps JS, Linder KE, Peredo C, et al. (2016) Early Activation of Th2/Th22 Inflammatory and Pruritogenic Pathways in Acute Canine Atopic Dermatitis Skin Lesions. J Invest Dermatol 136(10): 1961-1969.

53. Nuttall TJ, Knight PA, McAleese SM, Lamb JR, Hill PB (2002) T-helper 1, T-helper 2 and immunosuppressive cytokines in canine atopic dermatitis. Vet Immunol Immunopathol 87(3-4): 379384.

54. Arzi B, Clark KC, Sundaram A, Spriet M, Verstraete FJM, et al. (2017) Therapeutic Efficacy of Fresh, Allogeneic Mesenchymal Stem Cells for Severe Refractory Feline Chronic Gingivostomatitis. Stem Cells Transl Med 6: 1710-1722. 
55. Leibacher J, Henschler R (2016) Biodistribution, migration and homing of systemically applied mesenchymal stem/stromal cells. Stem Cell Res Ther 7: 7 .

56. Ra JC, Kang SK, Shin IS, Park HG, Joo SA, et al. (2011) Stem cell treatment for patients with autoimmune disease by systemic infusion of culture-expanded autologous adipose tissue derived mesenchymal stem cells. J Transl Med 9: 181.

57. Glenn JD, Whartenby KA (2014) Mesenchymal stem cells: Emerging mechanisms of immunomodulation and therapy. World J Stem Cells 6: 526.

58. Boehncke W-H, Schön MP (2007) Animal models of psoriasis. Clin Dermatol 25(6): 596-605.

59. Lowes MA, Kikuchi T, Fuentes-Duculan J, Cardinale I, Zaba LC, et al. (2008) Psoriasis Vulgaris Lesions Contain Discrete Populations of Th1 and Th17 T Cells. J Invest Dermatol 128(5): 1207-1211.

60. Liu R, Wang Y, Zhao X, Yang Y, Zhang K (2014) Lymphocyte inhibition is compromised in mesenchymal stem cells from psoriatic skin. Eur J Dermatol 24(5): 560-567.

61. Shin TH, Lee BC, Choi SW, Shin JH, Kang I, et al. (2017) Human adipose tissue-derived mesenchymal stem cells alleviate atopic dermatitis via regulation of $B$ lymphocyte maturation. Oncotarget 8(1): 512-522.

62. Ferrara JL, Levine JE, Reddy P, Holler E (2009) Graftversus-host disease. Lancet 373: 1550-1561.

63. Brüggen MC, Klein I, Greinix H, Bauer W, Kuzmina Z, et al. (2014) Diverse T-cell responses characterize the different manifestations of cutaneous graft-versushost disease. Blood 123(2): 290-299.

64. Aggarwal S (2005) Human mesenchymal stem cells modulate allogeneic immune cell responses. Blood 105(4): 1815-1822.

65. English K, Ryan JM, Tobin L, Murphy MJ, Barry FP, et al. (2009) Cell contact, prostaglandin E(2) and transforming growth factor beta 1 play nonredundant roles in human mesenchymal stem cell induction of $\mathrm{CD} 4+\mathrm{CD} 25$ (High) forkhead box P3+ regulatory T cells. Clin Exp Immunol 156(1): 149-160.
66. Locatelli F, Algeri M, Trevisan V, Bertaina A (2017) Remestemcel-L for the treatment of graft versus host disease. Expert Rev Clin Immunol 13(1): 43-56.

67. Wahren-Herlenius M, Dörner T (2013) Immunopathogenic mechanisms of systemic autoimmune disease. Lancet 382(9894): 819-831.

68. Asari S, Itakura S, Ferreri K, Liu CP, Kuroda Y, et al. (2009) Mesenchymal stem cells suppress B-cell terminal differentiation. Exp Hematol 37(5): 604-615.

69. Liang J, Zhang H, Hua B, Wang H, Lu L, Shi S, et al. (2010) Allogenic mesenchymal stem cells transplantation in refractory systemic lupus erythematosus: a pilot clinical study. Ann Rheum Dis 69(8): 1423-1429.

70. LeRoy EC, Medsger TA (2001) Criteria for the classification of early systemic sclerosis. J Rheumatol 28: 1573-1576.

71. Fuschiotti P (2016) Current perspectives on the immunopathogenesis of systemic sclerosis. Immunotargets Ther 5: 21-35.

72. van Rhijn-Brouwer FCC, Gremmels H, Fledderus JO, Radstake TRD, Verhaar MC, et al. (2016) Cellular Therapies in Systemic Sclerosis: Recent Progress. Curr Rheumatol Rep 18(2): 12.

73. Maria ATJ, Toupet K, Bony C, Pirot N, Vozenin MC, et al. (2016) Antifibrotic, Antioxidant, and Immunomodulatory Effects of Mesenchymal Stem Cells in HOCl-Induced Systemic Sclerosis. Arthritis Rheumatol 68(4): 1013-1025.

74. Akiyama $\mathrm{K}$, Chen $\mathrm{C}$, Wang D, Xu X, Qu C, Yamaza T, et al. (2012) Mesenchymal-Stem-Cell-Induced Immunoregulation Involves FAS-Ligand-/FASMediated T Cell Apoptosis. Cell Stem Cell 10(5): 544555.

75. Scuderi N, Ceccarelli S, Onesti MG, Fioramonti P, Guidi C, et al. (2013) Human Adipose-Derived Stromal Cells for Cell-Based Therapies in the Treatment of Systemic Sclerosis. Cell Transplant 22: 779-795.

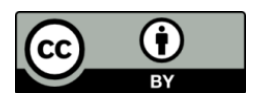

